\title{
O nacionalismo de Alexandre Levy em suas variations sur un thême populaire brésilien
}

The nationalism of Alexandre Levy em suas Variations sur un Thême Populaire Brésilien

Henrique Segala Villela ${ }^{1}$ Instituto de Artes da Universidade Estadual Paulista (UNESP) 


\section{Resumo}

O presente artigo investiga o nacionalismo de Alexandre Levy (1864 - 1892) através do levantamento bibliográfico, compreendendo o contexto histórico, um resumo biográfico do compositor e o estudo de suas correspondências com os ideais de modernidade e identidade nacional da "geração de 1870" e outros intelectuais de seu tempo. Por fim, também coleta informações relevantes e analisa comentários publicados sobre as Variações sobre um tema popular brasileiro (1887), além de realizar uma pequena análise musical. O objetivo foi esclarecer o pensamento do compositor e suas intenções ao compor a obra em questão. Pôde-se deslumbrar um nacionalismo musical que não era exclusivo de Alexandre Levy, mas compartilhado por contemporâneos e que apresenta uma proeminente faceta cosmopolita.

Palavras-chaves: Alexandre Levy, Nacionalismo musical brasileiro, Geração de 1870, Musicologia.

\section{Abstract}

This article examines Alexandre Levy's (1864 - 1892) nationalism through bibliographic research, comprising the historical context, a composer's biographical sketch and the study of his correspondences with the ideals of modernity and national identity from "generation of 1870" and other contemporary intellectuals. Finally, it also collects relevant information and examines published comments about the Variations on a popular Brazilian theme (1887), besides accomplishing a brief musical analysis. The objective was to clarify the composer's thought and his intents on writing the work in question. A musical nationalism that wasn't peculiar to Alexandre Levy, but was shared by his contemporaries as well and which presents a prominent cosmopolite face has been unveiled.

Keywords: Alexandre Levy, Brazilian musical nationalism, Generation of 1870 , Musicology.

\footnotetext{
${ }^{1}$ Iniciou aulas de piano aos 8 anos de idade com a professora Marisa Farinelli em sua cidade natal Jundiaí, São Paulo. Prosseguiu seus estudos no Instituto Cultural e Musical "Dr. Gomes Cardim", sob orientação de Ulisses Dumalakas, onde concluiu o curso técnico em Habilitação Musical - Piano. É bacharel em Música - Instrumento - Piano pelo Instituto de Artes da Universidade Estadual Paulista (UNESP), tendo estudado com o Prof. Dr. André Rangel. Participou em masterclasses com Paulo Steinberg, Renato Figueiredo, Gilberto Tinetti, Ney Fialkow, Flávio Augusto, Gigla Katsarava e Cristina Ortiz. Desenvolve suas atividades em música de câmara, contemporânea, brasileira e correpetição, além de se apresentar frequentemente como solista.
} 


\section{Introdução}

Embora Alexandre Levy (1864 - 1892) seja amplamente reconhecido como precursor do movimento nacionalista pela historiografia musical brasileira, há poucos estudos que investiguem sua contribuição e importância (TUMA, 2008, p. 11-12). Essa visão já foi questionada por Camila Segala (2003) e Said Tuma (2008) e tem-se delineado uma nova compreensão para a figura do compositor paulistano, menos influenciada pelo Modernismo de 1922 e mais condizente com o seu tempo. Entre suas composições, a obra Variations sur un thême populaire brésilien (Variações sobre um tema popular brasileiro, 1887) é a primeira a revelar uma reflexão sobre o aspecto nacional na música e uma das primeiras a utilizarem um tema popular no Brasil (AZEVEDO, 1956, p.157) (MARIZ, 1994, p. 119).

Como primeiro passo no intuito de investigar a presença e a natureza do nacionalismo na abordagem composicional de Levy, a exemplo da obra em questão, serão apresentados neste texto certos aspectos de sua biografia, assim como do ambiente cultural e contexto histórico em que viveu. Indícios podem ser percebidos em relação às próprias origens do movimento nacionalista musical brasileiro.

A base para a realização desta pesquisa ${ }^{1}$ foi o levantamento bibliográfico: historiografia musical brasileira, trabalhos monográficos sobre Alexandre Levy, além de outros materiais que contribuíssem com a bibliografia utilizada. A partir dessa leitura, redigiram-se um resumo biográfico e um breve panorama socioeconômico e cultural de São Paulo. Foi importante observar a proximidade do compositor com a chamada "geração de 1870" e o reflexo desse ideário em seu pensamento e atividade. Além disso, coletaram-se dados sobre as Variações e realizou-se uma breve análise musical a partir dos comentários e apreciações encontrados e da observação do tratamento dado ao tema e outros parâmetros, como harmonia e contraponto.

Consultaram-se o Acervo da Fundação Biblioteca Nacional - Brasil e do periódico O Estado de São Paulo (ou A Província de São Paulo, antes da proclamação da República). Este último, disponível pela Internet ${ }^{2}$, revelou vários artigos, críticas de concerto e anúncios bastante enriquecedores para a bibliografia utilizada, contribuindo até mesmo como documentação histórica. A ortografia original das citações foi mantida e optouse pela análise harmônica tradicional (com algarismos romanos).

\section{SÃO PAULO: VERTIGINOSA TRANSFORMAÇÃO}

No início da década de 1870, São Paulo era uma pacata cidade de aproximadamente 23 mil habitantes (CARONE, 1978 apud MORAES, 1997, p. 66). Ainda preservava as características de seu passado colonial, em um ambiente rural e provinciano. A vida

\footnotetext{
$1 \quad$ O autor agradece, especialmente, ao Prof. Dr. André Luís Silva Rangel pela orientação.

2 Acervo Estadão. Disponível em: <http://acervo.estadao.com.br/>. Acesso em 24 de novembro de 2015.
} 
cultural de então resumia-se principalmente à Academia de Direito, cujos estudantes filhos de famílias abastadas de várias partes do Império - organizavam serestas, serenatas, saraus literários e peças teatrais, além de participarem da imprensa local (MORAES, op. cit., p. 34-36). No entanto, a expansão da cafeicultura pelo oeste paulista e, consequentemente, da malha ferroviária - que tem a cidade como importante entroncamento - foi catalisadora de uma intensa transformação durante a segunda metade do século XIX e início do seguinte.

Diante de um crescimento populacional exponencial e da expansão desordenada da área urbana, a elite, que começa a se enriquecer e vê na cidade um ponto estratégico para administrar os seus negócios entre o interior e o porto de Santos, manifesta preocupações quanto à urbanização. Foi durante a administração de João Teodoro, presidente da província entre 1872 e 1875, que se iniciaram as obras de embelezamento: calçamento, ampliação e arborização de ruas, construção e reforma de praças, modernização da iluminação pública, entre outras (MORAES, op. cit., p. 38-39, 45-46).

A nova arquitetura da cidade (principalmente nos bairros residenciais nobres e no centro) revela com nitidez o cosmopolitismo dessa elite: era uma "miscelânea de estilos" (Ibid, p. 41). Nas últimas décadas do século XIX, desprezava-se tudo o que evocasse o passado colonial - incluindo grupos sociais e manifestações culturais - e se adotavam hábitos e ideias europeus (TUMA, op. cit., p. 58-60).

\section{BIOGRAFIA}

\subsection{A Casa Levy}

Em 1860, Henrique Luís Levy - clarinetista amador judeu-francês da Alsácia-Lorena que viera ao Brasil em $1848^{3}$ - funda a joalheria Ao Bouquet de Brilhantes. Com o tempo, o negócio se transforma na Casa Levy, voltando-se exclusivamente para a música: comercializa instrumentos, partituras, métodos de ensino e livros sobre artes (GONÇALVES, 1995, p. 57-60).

Apesar de não estar confirmada a existência de um café junto à loja (SEGALA, 2003, p. 41), a Casa Levy se tornou um ponto de encontro para estudantes da Faculdade de Direito e importantes figuras da elite paulistana. Músicos de passagem pela cidade (inclusive regentes e cantores das temporadas líricas) se dirigiam ao estabelecimento, que funcionou como "uma agência informal de empregos" para professores de música e de

\footnotetext{
3 As agitações revolucionárias de 1848 e o anti-semitismo provavelmente estão entre as causas de sua imigração (FALBEL, 2008, p. 408-409). Durante o século XIX, uma quantidade significativa de judeu-franceses, a maioria oriunda da Alsácia-Lorena, veio ao Brasil (VIDAL; LUCA, 2009, p. 175-178). Embora os destinos preferenciais dos franceses - judeus ou não -, no Brasil, fossem Rio de Janeiro, Salvador e Recife, São Paulo foi um dos locais onde sua influência se mostrou mais marcante: foram essenciais para "o tom de civilidade e aperfeiçoamento de serviços especializados, em particular no comércio fino" (Ibid., p. 29). "O crescimento da cidade, o aproveitamento endógeno do lucro cafeeiro, o 'aburguesamento' das elites [...] abriram espaço para o consumo de artigos importados e de serviços, de modo especial da França" (Ibid., p. 228). É interessante notar que a influência cultural francesa era tamanha a ponto de mesmo franceses sem conhecimento e experiência conseguirem se inserir nesse mercado como modistas, alfaiates, cabeleireiros, etc. (Ibid., p. 214-215) e que foi comum dar nome francês a estabelecimentos comerciais, independentemente da nacionalidade do proprietário (Ibid., p. 197-199).
} 
línguas recém-chegados à capital (GONÇALVES, op. cit., p. 121-122). A Casa também foi espaço para várias audições musicais e foi considerada, durante certo tempo, o centro musical da cidade de São Paulo.

\begin{abstract}
"Não é demais imaginar o importante papel que deve ter representado esse espaço musical para o jovem Alexandre, seja como provedor de recursos materiais através de partituras e instrumentos que eram comercializados pela Casa, seja pelos importantes contatos que deve ter travado com inúmeras personalidades que por ali passavam" (TUMA, op. cit., p. 51).
\end{abstract}

Vale enfatizar: não só com músicos, mas também com outros intelectuais da época e membros da elite paulistana.

\title{
3.2. Alexandre Levy
}

Nasceu em São Paulo, 10 de novembro de 1864, o segundo dos quatros filhos de Henrique Luiz Levy e Laurette Chassot. Esta, uma suiça católica. Aquele, como mencionado anteriormente, um francês de origem judaica ${ }^{4}$. Apesar de não haver muitos indícios, parece que a religião adotada pela família foi a católica: encontrou-se um convite à missa do $7^{\circ}$ dia da morte de Alexandre (O Estado de São Paulo, 1892b). Segundo Camila Segala, os negócios do pai proporcionaram à família uma vida tranquila e boa posição na sociedade paulistana (op. cit., p. 42).

Desde cedo, interessou-se pela música. Seu irmão mais velho Luís foi quem o introduziu ao piano, prosseguindo os estudos com o russo Louis Maurice ${ }^{5}$ em 1872 . Pouco tempo depois, passou a ter lições com Gabriel Giraudon ${ }^{6}$ (que também ensinara ao irmão), sem abandonar a supervisão do professor anterior. Torna-se figura frequente nos concertos e recitais da cidade e é considerado um virtuose.

Começa a compor para piano aos doze anos (ACQUARONE, s. d., p. 228) (MARIZ, 1994, p. 119), mas os catálogos datam as primeiras composições em volta de 1880 (MARCONDES, 1998, p. 442) (SEGALA, op. cit., p. 90).

Voltando-se cada vez mais para a composição, após um período de autodidatismo iniciado em 1876 - "se dedicava seriamente ao estudo dos grandes mestres classicos e românticos, perlustrando com devoção as obras de Bach, Beethoven, Haydn, Mozart, Chopin, Mendelssohn e Shumann (sic)" (PIMENTA, 1908) -, Levy inicia aulas de harmonia e composição com Georg von Madeweiss ${ }^{7}$ em 1883. Dois anos mais tarde, prossegue

\footnotetext{
4 Picchi escreve que a família era de origem judaico-russa (2002, p. 26). Mas, na bibliografia consultada, não foi encontrada nenhuma outra fonte que o corroborasse.

5 A grafia desse nome varia nos textos pesquisados: Luís Maurício, Luís Maurice e Luiz Maurice; "segundo Carlos Penteado de Rezende, tinha sido discípulo de Schulhoff na Europa, fixou residência na paulicéia no [...] ano de 1869" (TUMA, op. cit., p. 89).

6 Pianista, regente e compositor francês. Discípulo de Thalberg, estudou nos conservatórios de Marselha e Paris. Veio ao Brasil em 1859 e, no ano seguinte, estabeleceu-se em São Paulo, onde viveu até sua morte, em 1906. Obteve grande prestígio como professor de música, especialmente de piano, tendo Henrique Oswald, Antonieta Rudge e Magdalena Tagliaferro como alunos (REZENDE, 1946d).

7 Barão prussiano de grande cultura musical, pianista e compositor. Veio ao Brasil em 1881, falecendo em 1885 (REZENDE, 1946c) talvez essa seja a causa que levou Levy à procura de outro professor.
} 
esses estudos com Gustavo Wertheimer ${ }^{8}$.

Em 1883, estudantes de direito e várias pessoas da sociedade paulistana se reuniram na Casa Levy, fundando o Club Haydn, importante marco na história musical de São Paulo. O clube tinha por finalidade promover concertos, com participação tanto de músicos amadores, quanto profissionais. Alexandre foi eleito diretor dos concertos e foi no $20^{\circ}$ concerto organizado pelo clube, no Teatro São José, em 31 de março de 1885, que Alexandre regeu uma orquestra pela primeira vez.

O último concerto da associação foi realizado no dia 10 de janeiro de 1887, com Levy ao piano executando Andante Spianato e Grande Polonaise Brilhante, op. 22 de Chopin, com acompanhamento de quinteto de cordas ${ }^{9}$.

Em 21 de maio de $1887^{10}$, pouco antes de partir para Europa , rege o primeiro ato de Freischütz de Weber no Teatro Provisório (CHICO, 1887) (A Província de São Paulo, 1887b).

No dia 31 do mesmo mês, A Província de São Paulo anunciava a partida de Levy, "afim de completar alli [Paris] seus estudos musicaes" (Id., 1887c).

Um texto bastante rico sobre essa viagem é de autoria de Carlos Penteado de Rezende (1946a, 1946b), que se baseia principalmente no relato de João Gomes Júnior, companheiro de Alexandre durante boa parte de sua estadia europeia. Primeiramente, Levy se hospedou em Milão durante os meses de março, abril e maio. Depois, dirigiu-se a Paris, onde foi assíduo frequentador dos concertos de Lamoureux e Colonne. Apresentou-se no renomado Conservatório de Paris, levando consigo as cartas de recomendação que trouxera do Brasil. Embora a escola estivesse em férias, conseguiu algumas aulas particulares com Émile Durand e Vincenzo Ferroni. No entanto, sentindo-se sozinho e acometido de uma enfermidade, Levy é orientado por médicos a retornar ao Brasil. Em novembro de 1887, parte de volta a São Paulo (Id., 1946b).

Exerce também o papel de crítico musical. Sob pseudônimo de Figarote, publica pela primeira vez em 10 de dezembro de 1889, no Correio Paulistano, e assim o faz até, aproximadamente, abril de 1891.

Falece subitamente no dia 17 de janeiro de 1892, enquanto jantava com a família.

\section{LEVY E A GERAÇÃO DE 1870}

Em sua dissertação de mestrado, Said Tuma aponta a proximidade de Levy com a "geração de 1870". Sobretudo porque as atividades de Levy como crítico musical e diretor do Club Haydn revelam um engajamento, um sentimento de "missão" (SEGALA, op. cit., p. 97-98) que foi comum entre os intelectuais da belle époque brasileira (TUMA, op. cit., p. 29-30,102). É interessante notar que outro compositor também propalado como

8 Há divergências nas fontes: algumas afirmam que era alemão (TUMA, op. cit., p. 51) (REZENDE, 1946c); outras, austríaco (MARCONDES, op. cit., p. 441) (SEGALA, op. cit., p. 46) (REZENDE, 1946a).

9 Há divergências nas fontes: algumas afirmam que era alemão (TUMA, op. cit., p. 51) (REZENDE, 1946c); outras, austríaco (MARCONDES, op. cit., p. 441) (SEGALA, op. cit., p. 46) (REZENDE, 1946a).

10 O fechamento do Club Haydn é sempre atribuído a essa viagem. No entanto, se o último concerto do grêmio foi em janeiro e, depois, Levy teve tempo de organizar a encenação de uma ópera antes de partir, o fim das atividades do clube deve ter outras razões. 
um dos precursores do nacionalismo pela historiografia musical, Alberto Nepomuceno, teve estreita relação com o movimento (VIDAL, 2011, p. 115).

Outros indícios atestam essa hipótese: o constante contato com os estudantes de Direito que frequentavam a Casa Levy e o fato de ser "extraordinariamente apaixonado pela litteratura". Só para elucidar esse interesse, encontrou-se uma nota anunciando a criação de uma associação literária, Arcadia Paulistana, com Alexandre Levy entre seus sócios fundadores (A Província de São Paulo, 1889). O compositor nutria especial apreço pelo Naturalismo (PORTO-ALEGRE, 1892 apud TUMA, op. cit., p. 119), evidenciado pela escolha do romance A carne, de Júlio Ribeiro, como programa para o Samba (TUMA, op. cit., p. 55).

\section{1. Modernidade}

O movimento literario-intelectual surgiu na Faculdade de Direito de Recife, liderado por Tobias Barreto, em momento de grandes mudanças para o país: fim da Guerra do Paraguai (1865-1870), o Manifesto Republicano de 1870 e a campanha abolicionista. Com o objetivo de "buscar a integração do Brasil na cultura ocidental", tornava-se necessário modernizar as estruturas do país e elevar o nível cultural e material da população (VELLOSO, 2003 apud TUMA, op. cit., p. 114). Isso se traduziu em "uma constante preocupação em se atualizar com o modo de vida promanado da Europa, reconhecida como verdadeiro ideal de modernidade e civilização" (TUMA, op. cit., p. 13).

Segundo Tuma, "a análise dos artigos de Levy é bastante ilustrativa para mostrar o papel ocupado pela Europa e sua música nas concepções de progresso musical" (Ibid., p. 129). E a viagem à Itália e França, em 1887, pode ser considerada um marco, "pois a partir do seu regresso, o 'moderno' se torna para ele verdadeira obsessão" (Ibid., p. 11). Levy também tencionava ir a Bayreuth, a fim de conhecer mais da obra de Richard Wagner, considerada a música mais moderna em seu tempo (Ibid., p. 56).

Isso não significa que sintomas dessa "obsessão" não fossem presentes anteriormente. Seu interesse pela música orquestral, também incluída nesse conceito de modernidade, se evidencia nas atividades no Club Haydn; na composição da Sinfonia em mi menor, iniciada em novembro de 1886 (SENISE, 1985, p. 24) (MARCONDES, op. cit., p. 441); e no relato de Rezende sobre concertos que Levy assistiu em Milão, logo no começo da viagem: "a sua preferencia nesse tempo era decididamente pelo genero sinfonico e de camara" (1946a, 3a coluna, parágrafo 1).

Além da atividade crítica no Correio Paulistano, a direção do Club Haydn revela o engajamento de Alexandre Levy contra a incipiência da vida musical da cidade de São Paulo. Lutava por mais espaço para a música culta e preocupava-se com a educação musical do público paulistano, sendo "capaz de um sacrifício enorme de tempo, de dinheiro e de desgostos para realizar um concerto que educasse os seus co-estadinos" (REIS. In: PORTO-ALEGRE, 1892, p. 20 apud TUMA, op. cit., p. 114).

O compromisso com a modernidade também explica - junto ao cosmopolitismo e 
à aspiração ao progresso da elite paulistana, da qual a família Levy fazia parte - o ecletismo do conjunto de suas composições: "acompanhava de perto as matrizes da música européia" (TUMA, op. cit., p. 14). E isso se manifesta desde suas obras iniciais: "a ousada fantasia sobre os temas do Guarany, de Carlos Gomes, escrita aos dezesseis anos, [...] compreende o perfeito entendimento da época em que vivia e as transformações harmônico-melódicas por que se passava" (PICCHI, 2002, p. 28). E o próprio professor Giraudon reconhece as "tendencias um tanto ou quanto modernas ou avançadas" em uma das cartas de recomendação que Levy levou a Paris (REZENDE, 1946a, 2a coluna, par. 3).

\subsection{Nacionalismo}

A "geração de 1870" também encabeçou uma nova reflexão sobre o "popular" e a questão da identidade nacional. Se, no Romantismo, ao despertar do desejo por uma arte nacional, "o 'popular' era consubstanciado, grosso modo, na figura de um índio idealizado" (TUMA, op. cit., p. 116); os novos intelectuais (como Sílvio Romero e Araripe Júnior), influenciados pelo evolucionismo e naturalismo, introduziram o elemento negro em suas discussões e compreenderam "a nação [...] como resultado da progressiva transformação das matrizes européias pela ação do meio e da mistura de raças" (VENTURA, 1991, p. 37, grifo do autor). Essa percepção levou ao interesse pelo folclore, estudo científico (isto é, de acordo com as diretrizes positivistas) da cultura popular, "como elemento de diferenciação nacional" (TUMA, op. cit., p. 115).

Não obstante, no campo da música, a pesquisa folclórica fosse sistematizada apenas posteriormente, Levy demonstrou interesse em sua realização. Segundo João Gomes Júnior, amigo do compositor que o acompanhou durante boa parte de sua estadia europeia, ele dizia que "cada nação tinha a sua musica caracteristica e que o Brasil um dia haveria de revelar a sua. Afirmava que para escrever musica brasileira era preciso estudar a musica popular de todo o Brasil, sobretudo a do norte do país" (REZENDE, 1946b, 7ạ coluna). Segundo Tuma, a declaração deixa implícito que o folclore seria "uma espécie de solução para a questão da brasilidade" (op. cit., 117)

Primeiramente, é necessário discutir a veracidade desse relato. $O$ ensaio em que ele aparece tem a clara intenção de considerar Levy como o iniciador do movimento do nacionalismo musical (SEGALA, op. cit., p. 88). E, como Achille Picchi notou, "ou há coincidência de intenções [com o pensamento de Mário de Andrade] não realizadas por parte de Levy ou grandes esperanças, não completadas, de contextualizações nacionalistas" (op. cit., p. 29).

No entanto, não seria estranho que Levy assim pensasse, visto que Antônio Cardoso de Menezes (ex-acadêmico de Direito, crítico musical e amigo da família) assim se manifestou em ocasião da morte de Alexandre:

Elementos para formar uma escola nossa, é cousa que não nos falta; temol-os em prodigiosa abundancia. O que nos falta é a vontade determinada de reunil-os em grupo concreto e, a exemplo do que têm praticado os centros mais adiantados do velho mundo, sujeital-os ao trabalho da systematização, de onde possa 
emergir o movimento evolutivo e a solução final desse alto e fatal problema sociológico (PORTO-ALEGRE, 1892 apud TUMA, op. cit., 118).

Torna-se evidente que intelectuais da época já almejavam uma música nacional e acreditavam que o estudo do folclore era imprescindível a esse objetivo. Finalmente, 0 próprio Levy deixa transparecer seu interesse - e gosto - em suas críticas. É notável o apreço demonstrado pelo nacional na música espanhola no seguinte trecho:

Para finalizar o concerto, o sr. Toboso tocou só, uma deliciosa Bondalla[?] hespanhola, ou para melhor dizer um verdadeiro basar (sic) das daças (sic) nacionaes da Hespanha. Este trecho é realmente magnífico pela sua côr-local e pelo caracter essencialmente saleroso, que nos faz divagar sobre as bellezas andaluzas e sobre o poetico e sensual das muchachas do paiz de Calderon (FIGAROTE, $1890 \mathrm{~b}$ apud TUMA, op. cit., p. 162, grifo do autor).

Em outra ocasião, ao repreender a qualidade do repertório da Banda de Permanentes, pedindo-lhe "música mais elevada", Figarote faz uma ressalva:

Não queremos de maneira alguma eliminar do grupo musical de Permanentes as polkas, tangos e dobrados, pois é forçoso confessar que entre os nossos tangos muitos há que são verdadeiramente bons e que até representam a nossa musica popular" (FIGAROTE, 1890a apud TUMA, op. cit., p. 156).

Apesar de Levy não ser um folclorista, essa declaração evidencia que ele já possuía uma opinião sobre o que seria a música popular brasileira e quais as suas características definidoras.

\section{AS VARIAÇÔES}

\section{1. Data e local de composição; outras informações}

Sobre a data e local de composição das Variações sobre um tema popular brasileiro (ou, simplesmente, Variações), verificaram-se algumas divergências na bibliografia consultada. A versão da polianteia de Porto-Alegre (1892), publicada logo após a morte de Levy, foi abraçada por vários trabalhos posteriormente: Pimenta (1910), Almeida (1926), Bettencourt (1941), Kiefer (1976), entre outros. Para esses autores, o compositor as teria escrito em 1887, quando se achava em Paris, solitário e saudoso de sua terra natal, familiares e amigos (TUMA, op. cit., p. 45) (SEGALA, op. cit., p. 51).

Ao constatar, a partir do relato obtido de João Gomes Júnior, que Levy tocou as Variações em Milão - antes de ir a Paris, portanto -, Rezende observou uma "romantização do caso", concluindo que: 
Duas hipoteses ha para o caso: ou Alexandre escreveu a musica em São Paulo, ou, aproveitando um piano que ha sempre a bordo, escreveu-a durante a viagem, quando se achava ainda melancolico devido à partida e à solidão. Pode-se perguntar, tambem, se não foram compostas em Milão, imediatamente após a sua chegada (1946a, 3a coluna).

Azevedo (1956), Behague (1971), Segala (2003) e Tuma (2008) adotam essa nova conjectura (TUMA, op. cit., p. 46-7). Cabe ressaltar que Azevedo (op. cit., p. 157) supõe que a composição é dos "primeiros anos da mocidade" (embora não seja muito explícito, o musicólogo dá a entender que a peça pode ser anterior a 1887) e Mariz afirma que o ano de composição é 1884 - o que não foi averiguado em nenhum outro trabalho e pode ser um provável erro de digitação, pois o compositor contava "com pouco mais de vinte anos de idade" (1994, p. 119-120).

Esses dois últimos autores e Kiefer (1976, p. 109) são os únicos, na bibliografia consultada, que afirmam que a obra foi orquestrada pelo próprio autor posteriormente. Têm-se notícia de outras três orquestrações: Moreira de Sá (apenas das variações $\mathrm{n}^{\circ} 1$ a 6, 9, 13, 15 e 16) (O Estado de São Paulo, 1897), Léo Peracchi (Id., 1937) e Leopoldo Miguez (Id., 1922). Foi encontrado um manuscrito orquestral (s. d., 35 p.), não sendo possivel confirmar a autoria.

Sobre as edições da versão para piano encontradas, cumpre destacar uma americana (VORE et al., 1921). Nela, o tema original é omitido e a variação no 1, apresentada como o tema. As variações nos 4 e 12 (como referência, se utiliza as outras edições) também são excluídas: têm-se, portanto, treze variações e não dezesseis. Deve ser nessa edição (ou em outra semelhante) que Azevedo (op. cit.), Mariz (op. cit.) e Picchi (op. cit.) se baseiam em suas considerações sobre as Variações.

Foram encontradas referências a mais duas publicações da obra no exterior: em Buenos Aires (CHIAFFARELLI, 1891 apud SENISE, 1985, p. 23) e na Europa (PIMENTA, 1908).

\subsection{O tema}

Vem cá, Bitu (também conhecido como Cai, cai balão) remonta ao início do século XIX, sendo muito conhecido até hoje, em todo o país, como canção infantil (AZEVEDO, op. cit., p. 157) (PICCHI, op. cit., p. 29); "de acordo com o folclorista João Ribeiro, [...] se refere a uma dança de roda chamada 'siriri' ou 'ciriri' a qual tem duas versões, uma de Pernambuco e outra do Mato Grosso" (BEHAGUE, 1971 apud TUMA, op. cit., p. 44-5, rodapé, traduzido do inglês por Tuma). Sobre a origem do tema, José Vieira Fazenda descreve da seguinte forma:

De 10 de fevereiro a 17 do mesmo mês, em 1811, no Rio de Janeiro houve grandes chuvas, verdadeiro diluvio, a que o povo chamou "agua do monte", Tal acontecimento ficou perpetuado na cantiga "Vem cá, bitu". Do "vem cá bitu", ocupou-se o erudito dr. Francisco Augusto Pereira da Costa no seu "Folclore Pernambucano". Coloca porem a 
"agua do monte" no ano de 1817. [...] Segundo o dr. Joaquim Manuel de Macedo, o Bitú era um crioulo apaixonado de bebidas alcoolicas e soldado do batalhão dos Henriques. Cantava pelas ruas exibindo um boneco de molas e, convidado a cantar nas casas particulares, servia de mensageiro de recados amorosos. Afirma o autor que o Bitu morreu soterrado sob a cazinha (sic) que morava, a qual veio abaixo com o aguaceiro (apud CALDEIRA FILHO, 1946, par. 3).

O mesmo tema também foi usado por Alexandre Levy no Prelúdio de sua Suíte Brasileira (MARIZ, op. cit., p. 120) (PORTO-ALEGRE, op. cit. apud SEGALA, op. cit., p. 60).

\section{3. Breve Análise}

Se, para Behague, "as 16 variações não apresentam nenhum elemento local característico e não procuraram reconstruir uma atmosfera local" (1971 apud TUMA, op. cit., p. 45); Senise - que não reconhece Levy simplesmente como o precursor do nacionalismo (SEGALA, op. cit., p. 86-87) - afirma que "não será exagerado ouvir ecos de seresta" na variação no 10 (SENISE, op. cit., p. 21), provavelmente devido ao acompanhamento simples executado pela mão esquerda e o caráter lírico e improvisatório da voz superior (ou, em alguns compassos, das duas vozes superiores).

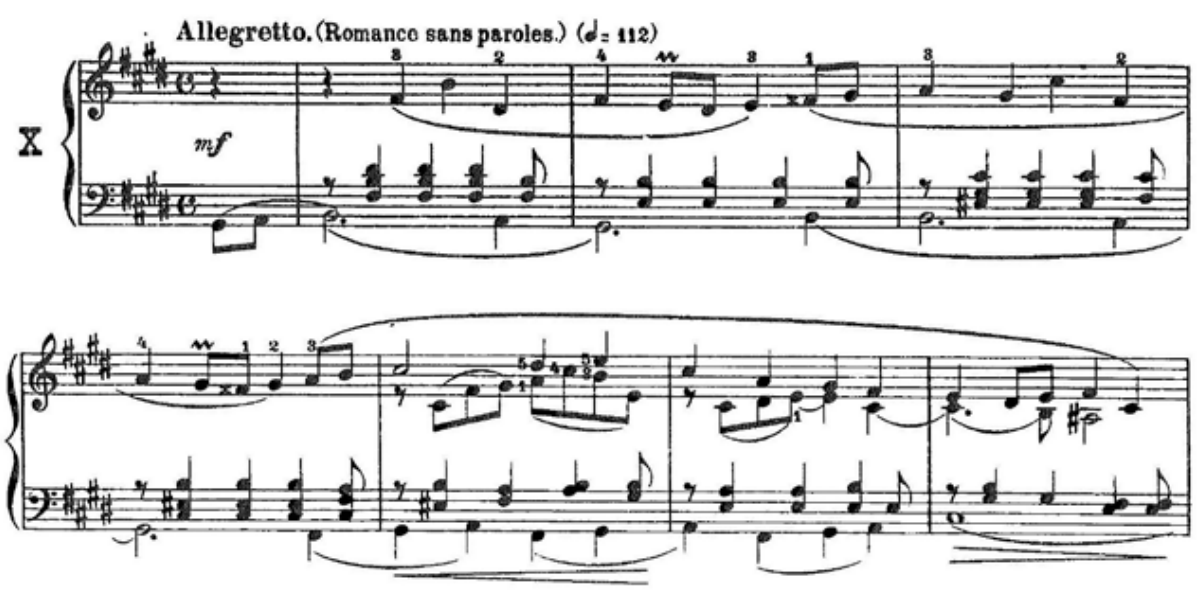

Figura 1: Início da variação no 10, na qual Senise identificou características de seresta

Entretanto o ambiente que prevalece nas Variações, como vários autores salientam, é o do Romantismo alemão, com destacada influência de Schumann (AZEVEDO, op. cit., p. 157) (KIEFER, op. cit., p. 109) (MARIZ, op. cit., p. 119-120) (PIMENTA, 1908, 1910) (BETTENCOURT, op. cit., p. 88) (CALDEIRA FILHO, op. cit.). Os dois compassos finais da variação no 9 são quase uma citação do tema dos Estudos Sinfônicos de Schumann, também compostos na forma de variações. 


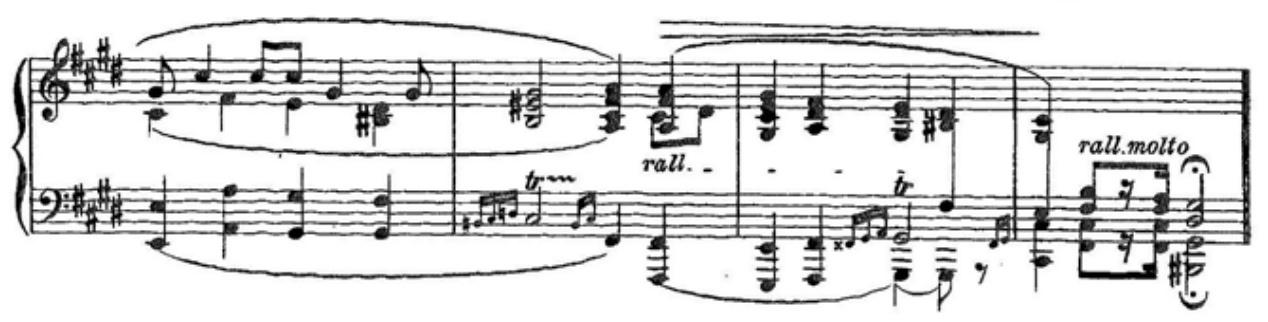

Figura 2: Compassos finais da Variação no 9

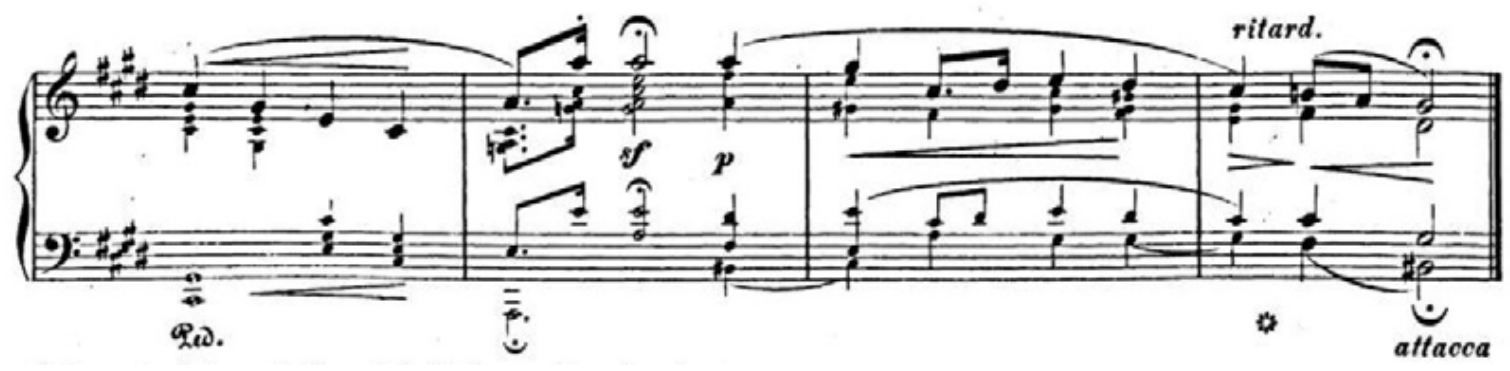

Figura 3: Compassos finais do tema de Estudos Sinfônicos op. 13 de Schumann

Adotando a versão de Porto-Alegre (1892) para a gênese das Variações - que, ironicamente, é contestada por Rezende na mesma página do jornal -, João C. Caldeira Filho (op. cit.) vê "rico subjetivismo" na maneira como Levy expôs o tema: "Nada mais simples e ingenuo do que a apresentação do tema na região média do instrumento, sem acompanhamento algum". Também nota a limitação instrumental ("fugazes incursões ao grave e ao agudo"), a ausência de drama e a permanência geral de um mesmo caráter - embora se afaste cada vez mais do tema -, atribuindo-as, sobretudo, às saudades que o compositor sentia.

No entanto, tendo em vista que as circunstâncias, durante a composição, devem ter sido outras e a perspectiva científica em torno do folclore que Levy parece adotar (TUMA, op. cit., p. 117-118), pode-se cogitar que a razão para tal escolha foi o cuidado em manter o tema na sua forma original, extraída do povo. Qualquer acréscimo ou alteração seria considerado interferência do compositor. A omissão de indicações como dinâmica e andamento, limitando-se a ligaduras de fraseado, corrobora essa hipótese

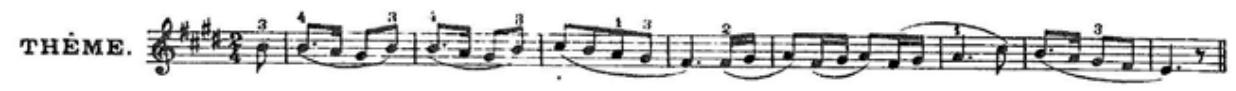

Figura 4: Tema das Variações, ausência de acompanhamento e de indicações como andamento e dinâmica

Considerando a ambientação da música popular urbana presente, segundo Behague (1971 apud TUMA, op. cit., p. 135), no Tango Brasileiro e no Samba, as características observadas por Caldeira Filho podem ser consideradas indícios de que o compositor deliberadamente não se afastou da ternura e singileza do tema ao longo da obra, evi- 
tando qualquer arroubo virtuosístico ou expressivo-dramático. É conveniente acrescentar que as dinâmicas pp e p são predominantes no decorrer da composição. Entretanto, as Variações foram uma tentativa inicial de ambientação, não tão bem-sucedida ${ }^{11}$ omo as duas outras obras posteriores citadas acima, em virtude da predominância de traços românticos.

A variação $n^{\circ} 1$ é uma harmonização a quatro vozes do tema que foge do esperado, introduzindo um acorde de mediante: apenas um acorde de Si menor na primeira inversão (v6 ou iv6/ii) e com duração de uma colcheia conecta o Mi maior (I) do compasso 2 ao Dó\# maior com nona menor do compasso seguinte (VI ou V7, 9b/ii). O compositor utiliza a relação de mediante no plano formal de uma forma muito interessante.

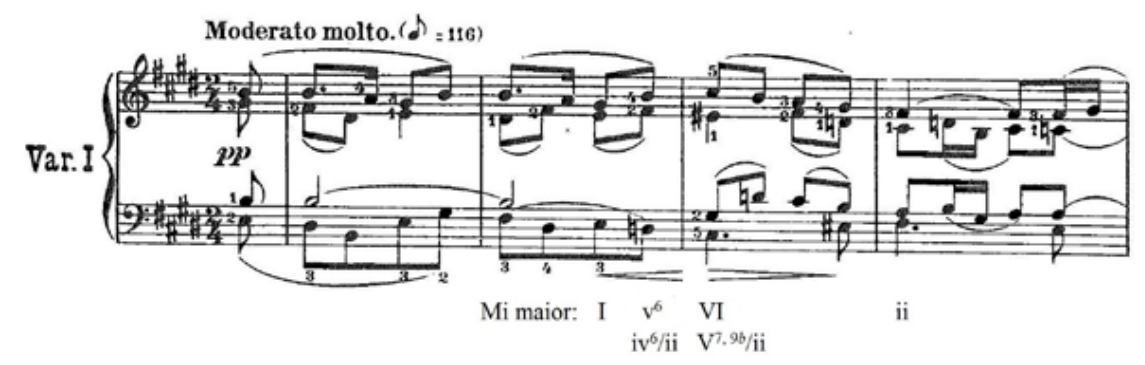

Figura 5: Variação no 1, harmonização do tema com acorde de mediante

Na variação $n^{\circ} 8$ (em Mi maior): um acorde de Sol\# maior com sétima e nona menor (V7,9b/vi) persiste por cinco compassos, mas não é resolvido convencionalmente. Trata-se de um recurso para conferir unidade com a variação seguinte, na tonalidade de Dó\# menor. Essa é bastante enfatizada ao longo da obra, sendo a tonalidade das variações de número 9, 13 e 14 (em Réb maior, ou seja, a tonalidade homônima ao enarmonizar-se para Dó\# maior). Outra tonalidade utilizada é a de Lá maior, nas variações 6, 11 e 15. Têm-se, portanto, duas relações mediânticas: entre Mi maior e Dó\# menor (vi) ou maior (VI) e, entre as duas últimas e Lá maior (VI/vi ou bVI/VI).

Outro trecho harmonicamente significativo ocorre na variação $n^{\circ} 9$, que termina no acorde de V6 (Sol\# maior na segunda inversão, cf. Figura 2), enquanto a seguinte se inicia no acorde de Si maior. Mas a relação mediântica tem uma atenuante: a passagem melódica Sol\#-Lá-Si no baixo (cf. Figura 1). Esse contraste, entretanto, não será suavizado entre as variações 14 e 15. Esta, em Lá maior, começando na nota Mi. Aquela, em Réb maior - o ponto mais afastado da tonalidade inicial a que se chega -, concluindo com uma bordadura sobre a terça do acorde (Fá). O compositor fez questão de realçar o cromatismo entre Fá e Mi entre estas duas variações. 

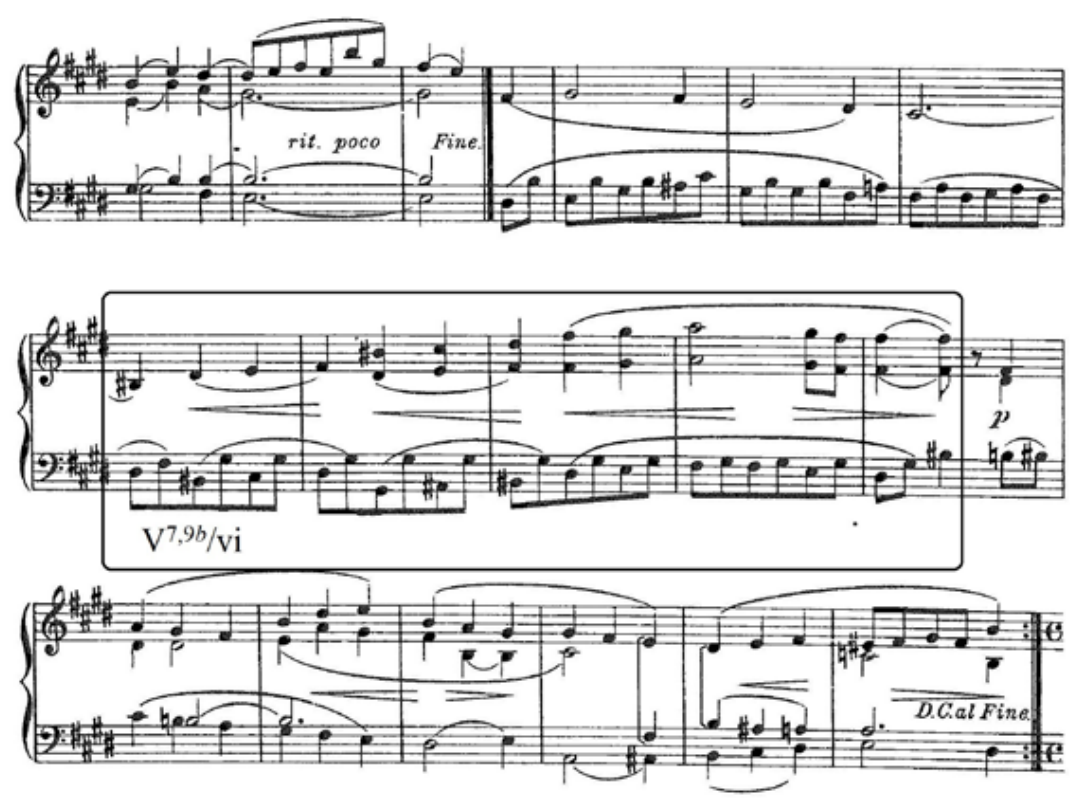

Figura 6: Variação no 8, acorde de dominante não resolvido convencionalmente

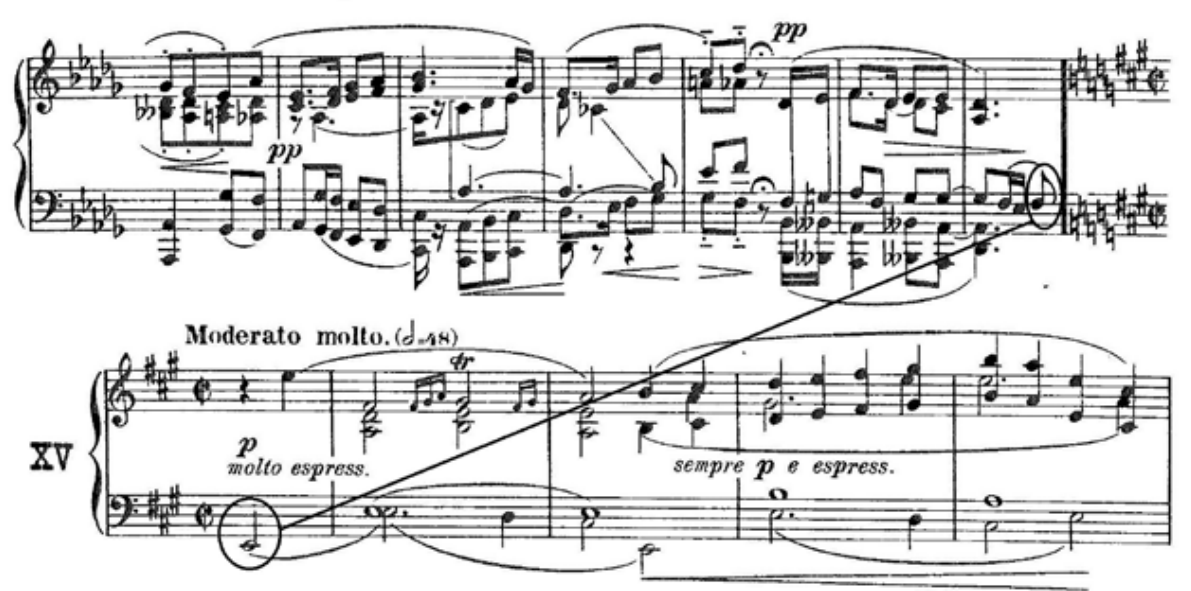

Figura 7: Cromatismo entre as Variações nos 14 e 15

Senise devia ter em mente passagens semelhantes a essa - a variação 2, por exemplo, possui duas vozes quase exclusivamente cromáticas - quando identificou "certas durezas nas sucessões harmônicas" como característica da escrita de Levy (op. cit., 21). A harmonia inusitada do compositor é frequentemente comentada pelos autores pesquisados e a presença de cromatismo e de relações mediânticas nas Variações ilustram a preocupação deste em estar atualizado às tendências da música europeia.

Os diversos procedimentos a que o tema é submetido também evidenciam a "formação profunda e acadêmica de Alexandre Levy" (PICCHI, op. cit., p. 29): exposto em uma voz intermediária (variações $n^{\circ} 4$ e 7$)$, no baixo $\left(n^{\circ} 5,8,10\right.$ e 15) ou alternando-se entre duas ou mais vozes ( ${ }^{\circ} 9$ e 13 ); há algumas variantes ( $n^{\circ} 2$ e 5 ); novos agrupamentos fraseológicos são construídos a partir de motivos do tema - que podem ser invertidos, transpostos e submetidos a outras modificações rítmicas e melódicas - $\left(n^{\circ} 6,9,14\right.$ 
e 16); entre outros.

\title{
6. CONSIDERAÇÕES FINAIS
}

\begin{abstract}
Ha muito tempo que era em S. Paulo o indefeso propagador de Beethoven, Haydn, Mozart, Mendelsohn (sic) e todos os grandes luminares da musica classica. Por isso talvez, as suas bellas composições, mesmo as mais simples e de assumpto nacional, eram repassadas desse sabor clássico. (O Estado de São Paulo, 1892a, par. 6)
\end{abstract}

Levy não só almejava a criação de uma música brasileira, como também deu alguns passos em sua direção. As Variações sobre um tema popular brasileiro representam uma primeira tentativa nessa busca: o tema é trabalhado de diversas formas mas evita-se afastar demasiadamente de seu caráter inicial. "O fato de que suas composições nacionalistas vieram nos últimos anos de sua vida é digno de nota, pois mostra que o aspecto nacionalista de sua produção não era meramente experimental e transitório" (BEHAGUE, op.cit. apud TUMA, op. cit., p. 125, traduzido do inglês por Tuma). E a forma como o compositor escolheu expor o tema evidencia, ainda que discretamente, um desejo pela sistematização do estudo folclórico.

Mas definir o compositor, simplesmente, como nacionalista - ou precursor do nacionalismo, como fez a historiografia musical brasileira influenciada pelos modernistas é ignorar a maioria de suas produções, com forma e estilo europeus: poemas sinfônicos e música de câmara, por exemplo. A produção nacionalista se resume a uma "trilogia" (ACQUARONE, s.d., p. 228): Variações, Tango Brasileiro e Suíte Brasileira (particularmente o quarto movimento, Samba); e a presença obrigatória da palavra brasileiro(a) nesses títulos evidencia sua exclusividade em relação ao conjunto de sua obra.

Sua formação e orientação europeia, fruto do cosmopolitismo da elite paulistana e da ânsia modernizadora da "geração de 1870" - além dos professores e da família, de origem europeia -, não são absolutamente incompatíveis com seu desejo por uma música nacional. Pelo contrário, era porque cada nação tinha a sua própria música que - Brasil também poderia ter a sua. O aproveitamento da linguagem musical classico-romântica - especialmente no que concerne à harmonia e influência de Schumann - e o título original, em francês, das Variações não devem ser vistos como contradição, mas elucidam a faceta cosmopolita do nacionalismo de Levy.

A presente pesquisa corrobora a nova perspectiva para Alexandre Levy - mais isenta da herança modernista e que o aproxima à "geração de 1870" -, delineada por Said Tuma (2008). A despeito da falta de um estudo folclórico sistematizado, tornou-se evidente que o compositor possuía uma concepção sobre o que seria a música popular brasileira. É necessário investigá-la e esclarecê-la para a melhor compreensão de suas intenções intelectuais. Uma nova revisão biográfica ${ }^{12}$ também se faz necessária, pois há 
momentos da vida de Alexandre Levy que ainda não estão esclarecidos a contento, em especial as circunstâncias que levaram ao fechamento do Club Haydn.

\section{REFERÊNCIAS BIBLIOGRÁFICAS}

ACQUARONE, Francisco. História da Música Brasileira. Rio de Janeiro: Paulo de Azevedo, [s.d].

ALMEIDA, Renato. História da música brasileira. Rio de Janeiro: F. Briguiet, 1926.

AZEVEDO, Luiz Heitor Corrêa. 150 anos de música no Brasil: 1800-1950. Rio de Janeiro: José Olympio, 1956.

BEHAGUE, Gerard. The beginnings of musical nationalism in Brazil. Monographs in musicology, Detroit: Information Coordinators, n. 1, p. 4-43, 1971.

BETTENCOURT, Gastão de. Temas da música brasileira - Conferências realizadas em Lisboa. Rio de Janeiro: A noite, 1941.

FALBEL, Nachman. Judeus no Brasil: estudos e notas. São Paulo: Humanitas; Edusp, 2008.

GONÇALVES, Janice. Música na cidade de São Paulo: o circuito da partitura. São Paulo, 1995. 316 f. Dissertação (Mestrado em História Social) - Faculdade de Filosofia, Letras e Ciências Humanas, Universidade de São Paulo, São Paulo.

KIEFER, Bruno. História da música brasileira, dos primórdios ao início do século XX. 1.ed. Porto Alegre: Movimento, 1976.

MARCONDES, Marco Antônio (Org.) Enciclopédia da música brasileira: popular, erudita e folclórica. 2 ed. São Paulo: ART Editora, 1998.

MARIZ, Vasco. História da música no Brasil. 4 ed. Rio de Janeiro: Civilização Brasileira, 1994.

MORAES, José Geraldo Vinci de. As sonoridades paulistanas - final do século XIX ao início do século XX. Rio de Janeiro: Funarte, 1997.

PICCHI, Achille. Alexandre Levy: paradigmas românticos e nacionalismo musical. ARTEunesp, São Paulo, v. 15, p. 23-33, 2002. 
PORTO-ALEGRE, Ignácio. Alexandre Levy: compositor e pianista brasileiro. Reimp. São Paulo: Casa Levy, s.d. (Polyanthéa publicada pela Gazeta Musical do Rio de Janeiro em 17 fev. 1892)

SEGALA, Camila Durigan. Alexandre Levy (1864-1892): uma revisão. São Paulo, 2003. 122 f. Dissertação (Mestrado em Música) - Instituto de Artes, Universidade Estadual Paulista.

SENISE, Arnaldo José. "Nota sobre o autor". In: LEVY, Alexandre. Sinfonia op. 21. Rio de Janeiro: Funarte, 1985.

TUMA, Said. O nacional e o popular na música de Alexandre Levy: bases de um projeto de modernidade. São Paulo, 2008. 202 p. Dissertação (Mestrado em Música) - Escola de Comunicações e Artes da Universidade de São Paulo.

VELLOSO, Mônica Pimenta. "O modernismo e a questão nacional". In: DELGADO, Lucilia de Almeida Neves; FERREIRA, Jorge (Org.). O tempo do liberalismo excludente: da Proclamação da República a Revolução de 1930. 2 ed. Rio de Janeiro: Civilização Brasileira, 2003. (O Brasil republicano, v. 1)

VENTURA, Roberto. Estilo tropical: história cultural e polêmicas literárias no Brasil, 18701914. São Paulo: Companhias das Letras, 1991.

VIDAL, João Vicente. Formação gêrmanica de Alberto Nepomuceno: estudo sobre recepção e intertextualidade. São Paulo, 2011. 343 p. Tese (Doutorado em Música) - Escola de Comunicações e Artes, Universidade de São Paulo.

VIDAL, Laurent; LUCA, Tania Regina de (Orgs.). Franceses no Brasil: séculos XIX-XX. São Paulo: Editora UNESP, 2009.

\section{Artigos de jornais e periódicos}

ALEXANDRE Lévy. O Estado de São Paulo, São Paulo, 19 jan. 1892. n. 5061. p. 1.

ALEXANDRE Levy. O Estado de São Paulo, São Paulo, 22 jan. 1892. n. 5064. Annuncios, p. 3.

ALEXANDRE Levy. O Estado de São Paulo, São Paulo, 15 set. 1922. n. 15943. p. 4.

ARCADIA Paulistana. A Província de São Paulo, 10 mai. 1889. n. 4230. p. 1.

CALDEIRA FILHO, João C. Vem cá, Bitu... . O Estado de São Paulo, São Paulo, 17 jan. 1946. n. 21683. p. 4. 
CHIAFFARELLI, Luigi. [Sem título]. Correio Paulistano, São Paulo, 25 mai. 1891.

CHICO, Don Gigadas el. [Sem título]. A Província de São Paulo, São Paulo, 24 mai. 1887. n. 3644. Chronica Semanal, p. 1.

FIGAROTE. Musica no Jardim do Lago do Palacio. Correio Paulistano, São Paulo, 11 mar. 1890. n. 10052. Palcos e Salões, p. 2.

Concertos. Correio Paulistano, São Paulo, 09 jun. 1890. n. 10125. Palcos e Salões, p. 2.

MUSICA. A Província de São Paulo, São Paulo, 15 nov. 1881. n. 2003. p. 2.

O Brasil no extrangeiro. O Estado de São Paulo, São Paulo, 19 jun.1897. n. 6790. Artes e artistas, p. 1.

OS meninos Levy. A Província de São Paulo, São Paulo, 29 jun. 1882. n. 2185. p. 2.

PARA a Europa. A Província de São Paulo, São Paulo, 31 mai. 1887. n. 3650. p. 2.

PARA dous piano. A Província de São Paulo, São Paulo, 25 jan. 1882. n. 2062.p. 3.

PIMENTA, Gelasio. Alexandre Levy. O Estado de São Paulo, São Paulo, 23 mar. 1908. n. 10697. p. 3.

[Sem título]. (Trabalho apresentado ao Instituto Historico e Geographico de S. Paulo) In: CELSO, Affonso. Instituto Historico. O Estado de São Paulo, São Paulo, 21 out. 1910. n. 11635. Movimento associativo, p. 7-8.

REZENDE, Carlos Penteado de. Alexandre Levy na Europa em 1887: I. O Estado de São Paulo, São Paulo, 17 jan. 1946. n. 21683. p. 4.

. Alexandre Levy na Europa em 1887: II. O Estado de São Paulo, São Paulo, 19 jan. 1946. n. 21685. p. 4.

A primeira professora de piano a apresentar alunas em concerto em São Paulo.

O Estado de São Paulo, São Paulo, 04 abr. 1946. n. 21747, p. 4.

. Gabriel Giraudon. O Estado de São Paulo, São Paulo, 01 mai. 1946. n. 21769, p. 4-5. 
SENISE, Arnaldo José. A harmoniosa lição de modéstia de um mestre. O Estado de São Paulo, São Paulo, 9 mar. 1980. n. 32204. Suplemento Cultural, p. 6-7.

SOCIEDADE BANDEIRANTE DE RADIO DIFFUSÃO. Inauguração official: programa. O Estado de São Paulo, São Paulo, 06 mai. 1937. n. 20728. p. 1.

THEATRO Provisorio. A Província de São Paulo, São Paulo, 24 mai. 1887. n. 3644. p. 2.

\section{Partituras}

LEVY, Alexandre. "Variations sur un Thême Populaire Brésilien". In: VORE, Nicolas de et al. (Ed.). The World's Best Music. New York: The University Society, 1921. v. 1. (Disponível em: <http://archive.org/details/worldsbestmusicl00werf>. Acesso em: 09 out. 2013.)

. Variations sur un Thême populaire Brésilien. 3 ed. São Paulo: Casa Levy, 1926.

Partitura. Piano. (Acervo da Fundação Biblioteca Nacional - Brasil)

SCHUMANN, Robert. Etüden in Form von Variationen (Symphonische Etüden): op. 13. Leipzig: Breitkopf \& Härtel, 1887. Partitura. Piano.

VARIAÇÕES SOBRE UM THEMA POPULAR BRAZILEIRO. Manuscrito, [s.d.]. 35 p. Partitura. Orquestra. (Acervo da Fundação Biblioteca Nacional - Brasil) 